\title{
Affirmative Action in Muslim China: The Impact on Young Women
}

\author{
David Makofsky \\ Research Anthropologist, Ethnic Minorities Studies Center \\ MinzuDaXue (Minorities University of China) Beijing, China
}

\begin{abstract}
Programs with the name 'Affirmative Action' had their origin in the UI.S. in the 1960's as a response to the civil rights movement. They were designed to bring some measure of equality to disadvantaged groups. These programs have now been applied on a worldwide scale, often as part of nation building. This study presents the choices and challenges surrounding the education of three young Muslim women in China. The Muslim Uyghur population of Xinjiang, China numbers over eight million, a small minority among the over a billion Han Chinese. The Uyghurs have never effectively integrated into China. The language of those native to the area is Uyghur-Turkish, and it is difficult for a Uyghur student on any educational level to be as linguistically fluent in Mandarin Chinese as a Han Chinese. Young Uyghur women, the subject of the interviews, have a set of choices regarding identity: are they primarily Uyghur and Muslim, or Chinese? If they identify with their culture as Uyghur and Muslim, there are restrictions on their opportunities as Chinese citizens. As students at Minorities University of China (MUC) in Beijing, an "affirmative action" university program, the relative freedom of Beijing has a great impact on these students. Education and employment opportunities are available that might not be available in their home province, Xinjiang. Termed in China as "affirmative action", schools of ethnic studies, provide opportunities for Uyghurs, especially for women.
\end{abstract}

\section{Introduction}

The term "Affirmative Action" had its origins in the United States in the early 1960's as legislation was passed to promote non- discrimination.
Affirmative Action soon became associated with legislation designed to promote positive discrimination, an effort to have some measure of equality for historically disadvantaged groups. The programs, typically in education, employment and housing, come out of the civil rights movement in the US. The focus was on an equality of opportunity for members of disadvantaged ethnic groups in a pluralist, ethnically diverse society.

Affirmative action in this positive form has been recognized as an effective tool for nation building on an international level. Canada, Australia and many European nations have had to come to terms with ethnically diverse immigrant populations. India and South Africa, with enormous problems of social integration, have implemented extensive affirmative action programs [6]. The Peoples Republic of China has an extensive affirmative action program as well. Sautman presents a full description of this [14].

Its politically conservative opponents immediately recognized the negative consequences of affirmative action. Programs aimed at ethnic diversity help some of the target group, but discriminate against others. The following quote points out that there are losers as well as winners in affirmative action programs, and the losers may not be those who were initially advantaged: "Take, for instance, the claim that racial preferences help the 'disadvantaged (in admissions at Stanford University).' In reality, as the Hoover Institution's Thomas Sowell has observed, preferences primarily benefit minority applicants from middle- and upper class backgrounds. At the same time, because admissions are a zero- sum game, preferences hurt poor whites and 
even many Asians (who meet admissions standards in disproportionate numbers). If preferences were truly meant to remedy disadvantage, they would be given on the basis of disadvantage, not on the basis of race." $[13,15]$.

The next arena of change may be Muslim awakenings of the Middle East and Central Asia, including Xinjiang. Affirmative action is playing a distinctive role Muslim China. This investigations deals with one Muslim group, the Uyghurs, a Turkic people of North West China primarily living in the Uyghur Autonomous Region of Xinjiang. The Uyghurs are closely related in language, culture and ethnicity to their Kazakh, Uzbek, and Turkmen neighbors, who live in Xinjiang and in neighboring countries.

The Uyghurs are a small group in terms of China's population of 1.3 billion, numbering 8.3 million. Although the region was formerly obscure, Xinjiang is a part of a wealthy and increasingly powerful modern China. The Uyghurs are a critical part of 'Islamic China'.

After the establishment of the People's Republic of China (PRC) in 1949 and the incorporation of Xinjiang into the PRC in the 1950's, the PRC made a substantial investment in the region. The province is rich in mineral resources. Xinjiang's economy by today's standards in China is relatively well off, although most Uyghurs are relatively poor.

\section{The role of Uyghur language education system (here called "affirmative action") in the integration of Uyghurs, especially women, in Chinese society}

Minority education, a school system and a university system in Uyghur, using Chinese as a second language operates in Xinjiang today.

Education in the Uyghur language extends to the highest university level, which provides language employment in the education system. There are Uyghur publications on a popular level as well as an academic level, and since Uyghur is an "official language", there are translation jobs as well. This is one part of affirmative action. It employs thousands of professionals and trains millions of students - see Sautman [14] Preferential Policies for ethnic minorities in China.
The development of these programs in Xinjiang was a historical necessity rather than the intention of the new government in 1949. The government had no means of educating the population other than to maintain the Uyghur language educational system in place in 1949. Few Uyghurs spoke Chinese and few Chinese spoke Uyghur [3, pp.193]. In areas other than education, the incorporation of an industrialized economy into the Xinjiang region of China did not occur rapidly. The Chinese government slowly built a province-wide system of public education in Chinese.

Today, a public education system in Chinese is available throughout the province, and both Han Chinese and Uyghur citizens of China can attend regular Chinese language schools if they can pass an all-Chinese entrance exam. Many do.

Also graduates of the Uyghur language elementary school programs can attend Chinese language middle schools, high schools and universities, but they must pass the entrance exam that is in Chinese. For entrance into the Uyghur language program, the exams are in Uyghur and Chinese as a second language. This policy is consistent with systems in place for other minorities,

A group of universities offer minority language and literature programs as well as a full university program in Chinese, and the universities are open to all students. One of these is the Minzu University of China, which has a school of Uyghur Studies, and also schools of Tibetan, Mongolian, and other Central Asian cultures. There are over fifty official minorities in China today, and the Uyghurs are one of the largest in number. As Chris Evans-Hearne [7, p.1] says: The Minzu University of China ... is a major ethnic minority university in China. Located in Beijing, approximately $70 \%$ of the students are non-Han Chinese minorities. The school has been designated as a Project 211 School. This means that the government gives the Minzu University of China special funding and support for the purpose of modernizing and improving the competitiveness of higher education in China."

Following Uyghur and Tibetan disturbances in recent years, minority language education in China is currently under attack by many inside and outside the Chinese government. Many in 
the Chinese Communist Party leadership believe these programs foster ethnic conflict. This is a time of conflict in Xinjiang, and schools maintained on the basis of ethnic identity are naturally suspected when issues of ethnic identity arise in the course of protest. A Uyghur faulty member in the ethnic minorities department of MUC has been detained by police, and initially some students were detained as well [5].

Another ground for attacking these programs is that the two systems are separate but not equal. There are those who claim that there are more effective ways to improve minority education. Mike Ives [9]: "Now there is growing concern that decades-old programs designed to help minority students are not effective. The proportion of ethnic minority students studying at Chinese universities has not kept pace with an expansion of the nation's higher education system, particularly at China's top-tier universities, said Gerard Postiglione, Director of the Wah Ching Center of Research on Education in China at the University of Hong Kong. China's ethnic minority instruction is failing to bridge the growing wealth disparity between coastal areas and its interior border regions, he added. "The Chinese government tends to paint a rosy picture by talking about how literacy is going up, but most people feel that in the market economy there's been a downturn in benefits for minorities."

Another criticism of the current system of affirmative action appears in a discussion by Rui Yang, Mei Wu [16, pp. 117-121]. Using scores on the all-Chinese college competitive entrance (the gaokao) Sautman reports that Han students admitted to Xinjiang universities in 1986 averaged 435 points in science and 440 points in liberal arts; whereas minorities averaged 300 points in science and 245 points in liberal arts. In 1987, Han students from Xinjiang admitted to national key universities averaged 472 points in science and 445 points in liberal arts; minority students averaged 313 and 269 points. There's a lot of debate about why China should perpetuate a minority education system which produces minority graduates who are poor compared to Han Chinese," concurred Dru Gladney, an anthropologist and expert in China's minority policies at California's Pomona College. "Under the old centralized system, the government used to spend a lot of money on the border areas," Gladney added. "But now they're relying on the market economy, and many of these ['nationalities'] universities have suffered as a result, because their funding hasn't kept pace."

\subsection{The Impact of the program on the Uyghur Population}

Table 1. Adapted from China Statistical Yearbook, 1999 [10]

Educational Attainment

1. Population

China 1.4 billion

Xinjiang 17.4 million

2. Natural Population Growth Rate

China $9.57 \%$

Xinjiang 12,8\%

\section{Percentage of Minorities}

China $<10 \%$

Xinjiang $61.4 \%$

4. Illiteracy Males 5 y.o. +

China $4.5 \%$

Xinjiang $4,7 \%$

5. Illiteracy Females 5y.o. +

China $11.3 \%$

Xinjiang $5.9 \%$

Students 6 y.o. +

6. Primary School China $39.7 \%$ Xinjiang $44.8 \%$

7. Secondary School China $43.7 \%$ Xinjiang $38.0 \%$

8. Higher Education China $2.7 \%$ Xinjiang $5,7 \%$

As we see in Table 1 Line 3, the region is largely "minority" in character. In 1949 the Han Chinese proportion was quite low, but the development of the region has led to the migration of ethnic Han Chinese to the area. Today, the Han Chinese population is concentrated in the Eastern portion of Xinjiang, and the Uyghur population is concentrated in the West. Not many Uyghurs have left Xinjiang province; one reason is that Uyghur, rather than Chinese, is the first language for the local population.

In Table 1 Line $2 \mathrm{We}$ see that the population growth rate in the province is nearly $33 \%$ higher than China as a whole. This is because the Uyghurs and other minorities are exempt from the "one child policy" of China. Instead of a nuclear family living in small urban apartments, in Xinjiang there is a large patriarchal Muslim family living in separate suburban houses. Other features of Uyghur identity serve to isolate them from the larger Chinese society. Uyghur dress is an issue, since women's use of headscarves and modest dress is unlike the Chinese style, and languages are different. In the Xinjiang region there is also residential separation into Uyghur districts and Chinese districts. There is also a long history of interethnic hostility. The hostility can occur on an interpersonal level, but there have been instances of rioting as well. Naturally, on a 
day-to-day level, there is also cooperation.

\subsection{Young Uyghur Muslim girls and educational barriers}

The historical circumstances that brought the Xinjiang Uyghur Autonomous Region into the New China in 1949 had major consequences for the Uyghur minority. Sources agree that in 1949 the Uyghur population, male and female, was largely illiterate. As Table 1 lines 4 and 5 demonstrate, the population is now largely literate in Uyghur, both for males and females. Uyghur female literacy in the region may now exceed the national average in the country. In the context of Central Asia, the literacy figures themselves also represent a dramatic achievement, since female educational attainment is one of the critical issues in Muslim society. Uyghurs and Han Chinese are literate in different languages. With the establishment of the New China in 1949, the remoteness of Xinjiang and the uncertainties of the new government necessitated the development of two separate school systems. Now that there are Chinese language schools in the Western part of the province, Uyghur families are free to send their children to Chinese schools, but in these schools the Uyghur students face the difficult challenge of receiving instruction in their second language.

Table I, lines 6 and 7 show what seems to have been happening to young Uyghur girls. Compared to the national average, fewer children attend high school in Xinjiang. Given the pattern of school attendance in China, it is widely believed that this is the result of Uyghur parental action.

This fall off in attendance may come from the fact that Uyghur girls are withdrawn from school. To control, perhaps to protect, their daughters, Muslim families encourage them to curtail their education and to marry partners chosen by their parents. Uyghur culture, which is Central Asian culture, has a long history of arranged marriage that continues up to the present time. Current research shows that young Uyghur men are given more freedom to choose their brides while Uyghur girls are offered little choice [14, Table I]. Comments made by participants in this study illustrate that controlling parents present obstacles to their children, such as the reluctance to allow their daughters to go to college outside their regional area.

Linda Benson observes [3], 'Available Chinese statistics on education (in Xinjiang) give rise to a number of questions. ... The statistics do not explain why, for example, the percentage of students (Uyghurs) continuing on to middle school remains relatively low. One factor may be the early withdrawal of girls from elementary school.'
Government figures from the 1990's have shown that young Uyghur girls often end their education with primary school.

Also, [3]: 'The government's undeniable successes [in raising the education level of minorities] are tempered by ongoing problems, some of which trace directly to the continued existence of two separate school systems - one for the minorities taught in their own languages and one offering instruction only in Chinese.

Uyghurs and other Muslim peoples link their concern to preserve their culture and identity with the language of instruction in the schools.' Uyghur schools may not effectively prepare children for assimilation into Chinese culture, but without these schools Uyghur culture itself may disappear. Chinese is taught in all Uyghur language schools

\subsection{Muslim women in a secular society}

Although few Uyghurs would admit this, one of the great advantages for women is that the government does not reinforce the family values of Xinjiang, in which many parents might prefer their daughters to stay in the area and marry young. In fact, a Uyghur high school teacher in a rural area near Kashgar reported that most of his students were young women. In rural areas women could not easily find "suitable jobs" and the young women simply refused to get married. In more urban areas, the teacher said, young women are getting jobs rather than getting married. The observations made about Uyghur women even a decade ago may be breaking down.

\section{Presenting Three Young Women}

\subsection{Aynur-Uyghur Identity and Career}

The young women who were interviewed are from large rural families. Aynur is a 22-year- old woman from a rural area of Kashgar. Kashgar itself is a large urban area with a population of 350,000 residents, over $90 \%$ Uyghur by the 2007 census. The town in which Aynur was raised is rural, with mostly small homes lacking indoor plumbing. Her family and neighbors are farmers. Until a few decades ago there was little motorized travel or rail traffic to the city.

As a young child, from 1990 to 1996, Aynur lived with her grandparents, her mother having left home for work after a divorce from her father. Her grandfather had a minor government position. Her grandparents lived in a society in which people were barely literate, and her grandfather could hardly read a document before he got his job.

Aynur's grandmother had been a teacher. The couple had six children. "One of my uncles liked reading; he lived in town and every Friday he came 
back and brought some books and told me about these books and read to me." Aynur's uncle was a factory worker. When she was old enough, Aynur went to primary school and read by herself. Her aunt taught her how to dance and sing. Aynur "was a smart girl so they had no complaints about my studies in school."

Aynur went to Uyghur schools because there were no Chinese schools in her area at that time. In 1949, at the time of the revolution, Xinjiang had been a region in which most local residents did not speak Chinese, so there were no textbooks for the local population other than those in the Uyghur language. A dual school system, one teaching basic subjects in Uyghur and the other teaching basic subjects in Chinese was established. The Uyghurs attended Uyghur language schools, and Aynur's education was in these Uyghur schools. This dual education system exists at the current time, but Uyghurs now have a choice of which school they wish to attend.

In the Uyghur school system, Aynur was considered very smart in the class and so the teachers favored her. "They expressed their love without any hesitation. Two teachers in high school showed me the good way to study and plan my life, and I believed them. I would not have (been able to) come to Beijing to study without their help. I believe that education can change a person. Good teachers can help students, and I want to help some students who need help."

If there is one institution that is the source of wide debate in modern China, it is the gaokao. This exam is not required for students who simply want a high school diploma, but each year the teen-age children who are planning to attend college in China take this national competitive exam. It relies heavily on memorized information and it continues for three days.

The challenge of the gaokao is especially difficult in Xinjiang. Most Uyghur families choose to send their children to Uyghur language schools. Uyghur language primary and secondary education is widespread in the province. If parents choose to send their children to Uyghur language schools, and the children want to study Uyghur language and literature at the university the children take the gaokao in Chinese as a Second Language. This requires a lesser knowledge of Chinese than that of a regular Chinese high school graduate, but also imposes a limited choice of majors in college.

Uyghur students can go to a regular Chinese university. To do this, they often go to school for one or two additional years to learn Chinese on a university level and prepare for the Chinese gaokao. Despite this, Uyghur parents believe if they do not send their children to Uyghur language schools, then Uyghur language and culture will be lost forever.

Aynur's gaokao was in Chinese as a Second Language, which meant that her college choices and her choices of major were limited. "I give thanks for gaokao, although I hated it. The gaokao changed my life. When I was a high school student I never thought about my future and college. I was scared of taking the gaokao. If you can't do well, you need to wait for one year and take it again. Without passing it, you have no chance to further your education." The Chinese as a Second Language gaokao is comprised of four parts: Chinese, Uyghur literature and language, mathematics, and a fourth comprehensive exam including history, politics, geography, physics, chemistry, and biology.

Aynur's score was one of the highest in her school so she had more choices of universities then her classmates. She chose the Minorities University of China (MUC) in Beijing, where she could get a full scholarship if she majored in Uyghur Language and Literature. Only two people in her school came to Beijing to go to college, which is a three-day train ride from Kashgar.

Aynur states that: "Maybe for some people, nation is not important as career. But for me and my (Uyghur) friends, we must think about this. In Beijing, we have good opportunity but for girls it is hard to find a Uyghur boy and raise a family. As a Uyghur girl, the family is very important for us. If I go back to Kashgar, perhaps I cannot advance in my career because my family has no connections. Kashgar does not have a large job market like Beijing, so I may not have any chance to prove my abilities for my career." What she means by this is that in Xinjiang it is difficult to find a good job if your family cannot help. This "help" represents family connections and influence and in China it is spoken of as guanxi. In Aynur's view, Aynur's larger job market in Beijing lessens the need for guanxi.

Beijing had been a dream to her, and this was something that her parents could not refuse. The choices between career and Xinjiang and choosing a major were very problematic for this young woman. Although her parents had been teachers, she is not fond of teaching. She feels that the curriculum in schools is too rigid and the job is too difficult. In addition to the regular curriculum, the students must attend extra Chinese society education classes that take up a great deal of the free time of students and the teachers. Aynur does not feel comfortable engaging in this work.

What she wants to do is to open up her own educational institution, perhaps a library, a place where she might have the freedom to educate young Uyghur children with her own curriculum. These are the plans of a young twenty two year old Uyghur woman. They may be difficult to realize, but they represent the attempt of a young woman to balance the strains of parents, opportunities, and the desire for personal independence.

\subsection{Meryam:The Opportunity to Investigate Culture}

The most dramatic example of a Uyghur woman exercising the ability to investigate the past is Meryam, a young woman of Kyrgyz- Uyghur descent who wears 
full Islamic dress. Unlike most others, she wears not simply a headscarf but an entire outfit of modest clothing. Like other Uyghur women, she majors in Uyghur language and literature. What she wants to do is go to school in Egypt to study Islamic education at a world famous institution, Al-Azhar University in Cairo. Founded during 970-972, it is the chief center of Arabic literature and Islamic learning in the world.

Additionally, she would like to visit Turkey. She has had the opportunity to study Turkish and Turkish culture at MUC. Her destination is the world of the Middle East. She then wants to work in Xinjiang as her life's choice. She believes Urumchi, the capitol and the largest city in the province, is the best place for her to work in Islamic education. She comes from a rural background. Her parents were poor farmers, and her grandparents were farmers as well. She has a sister who lives and studies Uyghur Language and Literature in Lanzhou University.

Courses in Uyghur Language and Literature at MUC Beijing and Lanzhou include the Islamic and old Turkish heritage of the Uyghur nation. Some students in the Uyghur language department at MUC choose to study "old Turkish," the Chagatai language, an extinct Turkic language which was once widely spoken throughout Central Asia, including Xinjiang, and remained the shared literary language until the early twentieth century. Specialists from Turkey serve as visiting professors in old Turkish. There are excellent sources of old Turkic history and culture, and the literature in English, Chinese, and Uyghur is growing.

\subsection{Radiyeh: Family Control and Women's Choices}

Radiyeh is a young woman from Kashgar who speaks excellent English in addition to being fluent in Uyghur and Chinese. Radiyeh's major is similar to the others, Uyghur Language and Literature, but unlike most of the other students, she wants to live away from Kashgar because her parents are too controlling. She faced great opposition from her parents when she wanted to go to school in Beijing, and it was only the fact that she scored well enough on the gaokao to attend a school as prestigious as MUC that they allowed her to leave Xinjiang and go to Beijing. In Xinjiang, Radiyeh is one of the first generation of women to deal with such issues. A university opportunity in the capitol of China was beyond the hopes of most Uyghurs from earlier generations. Radiyeh is also escaping from her family background, since her parents, brothers, and sisters are all farmers.

As Radiyeh says: "(In the old days,) the child of a farmer would marry a farmer - now a girl (a Uyghur college student) may be more educated than her boyfriend. In the time of her grandmother (the 1950's), the wife usually stayed at home."

Things are changing in Kashgar, but not quickly enough for Radiyeh, She would like to find a job in
Beijing, but even if she found a job back in Xinjiang, she would be reluctant to live near her parents. Issues such as leaving home, going out with boys, and finding a job are all problems in religiously conservative Uyghur families. The fact that Radiyeh went to Beijing was a great problem for her parents. Radiyeh said that in this respect, Xinjiang is like Afghanistan, which borders on Xinjiang on the West. This underlines how severe the limitations on Muslim women in Xinjiang can be. This issue may exist for women all over Central Asia.

Radiyeh is not necessarily worried about the choice of a job; she expected that she would be a teacher. With a major in Uyghur Language and Literature, this is one logical outcome for an educated Uyghur woman. Radiyeh is also interested in becoming a cultural worker, a journalist or one who works for a museum. Radiyeh hopes that she can get a better job in Urumchi, far across the province from Kashgar. Her first priority is personal freedom.

One of the things that weigh heaviest on Radiyeh's mind is the tradition of arranged marriage. Speaking about Central Asian family practices, Dami and Sheikh write: "In many senses, marriage is considered the union of two families, and the parents usually arrange the marriage. Although the free consent of both the bride and groom are essential, parental coercion is often strong. Some parents are evidently beginning to understand the marital concerns of their children." The practice of choosing marriage partners from within the parents' community of friends and business acquaintances, however, continues to be considered important by young and old [4]. Choosing a spouse may involve family members other than the immediate families of the couple, such as grandparents, aunts and uncles. The matter is further complicated by the high costs of elaborate weddings and dowry, which means the couple, will have to rely on parental financial support in order to marry. This in turn increases their dependency on parents and increases parental control.

Facing issues such as these means that a young Uyghur woman must confront her parents at an early age about her hopes and plans, when she is in her teenage years, or be bound to her parents' choice for the rest of her life. These traditions are changing, but young, ambitious women must decide their fate when very young.

\section{Minorities Studies, Affirmative Action, Social Change}

A major in Uyghur Language and Literature is general liberal arts major, including language, culture, and sociology in the first language of the student. Most of the undergraduate majors are young women, with young men perhaps preferring business or engineering. Most of those who major in this field of study do not have any life experience outside Xinjiang until they get to MUC in Beijing. In order to recruit good Uyghur 
students, MUC offers scholarships to students that major in Uyghur Language and Literature. On the graduate level, there are excellent jobs available in translation, since with eight million Uyghurs, there is a constant demand to translate documents back and forth from Uyghur to Chinese.

MUC students believe that the departments play a very positive role integrating them to the university and to modern China. Most of the students have not been outside Xinjiang before and comment on the friendships they have made with other Uyghurs at MUC. One freshman at the university reported that her parents were pleased that she made friends with other Uyghurs. In talking about her major, one student commented about an English class she had taken. In such classes, the professor talked the whole time, while in the Uyghur classes, the entire class participated and it was a more interesting class.

Students also mentioned the friendliness the Uyghur faculty and staff at the school. Uyghur parties and events feature faculty speakers, and at one graduation party, a leading faculty member congratulated all the participants individually. These events draw not only the students, but also the Uyghur community in Beijing, who bring their young children. Department events are posted on Uyghur web sites, and between the Internet and word of mouth, the Uyghur community in Beijing is well represented at Uyghur events at MUC.

As was shown in the case of Aynur and Maryam, these same departments heighten Muslim and Uyghur awareness and solidarity. The Internet and the school expose students to developments in the global Islamic community. They are exposed to speakers and to ideas that are not available in Xinjiang.

There is a great deal of support student support for Uyghur cultural academic programs on a University level.

It is an interesting fact that anthropologists that study ethnic education on an observational level have pointed out that Chinese methods of instruction, Chinese pedagogy, is usually inadequate for minority students throughout China.

In South West China, studying two ethnic groups Hansen concludes: "This study finds that standardized, homogenizing state education is in itself incapable of instilling in students identification with the Chinese state, ironically often increasing ethnic identity" [9].

Gerald Postiglione, editing collection on ethnic education in China, also concludes [11]: The material challenges us to think in more nuanced ways about the ambivalence of minority people about participating in the state-sponsored, Han-centered, standardized, testdriven, free and compulsory school system of the PRC."

As Aynur said "Our teachers at MUC are good, they have good personalities and they are supportive. There are chances to go abroad; they help us with employment, and provide information. We can learn everything about minority studies if we want. We are in Beijing. Beijing is our New York."

\section{Conclusion}

The argument against affirmative action programs does not take into account the real benefits for cultural identity. Although not apparent to outsiders, the 'push' for cultural change is very present in Xinjiang, especially among women. This change is an unintended direction, since it introduces students to membership in a larger world Muslim community.

The Minorities University of China provides the chance to participate in the liberalism of Beijing compared to the limitations in Xinjiang province. Experience in the university provides an opportunity for investigation of one's ethnic culture in a way that is not fully explored in Xinjiang. The opportunity to escape parental control is facilitated in college. Education and employment opportunities are the vehicles for group integration into larger Chinese society.

Ethnically oriented institutions such as the Uyghur Department of Language and Literature, which might appear to further separate young people from the Chinese society, actually help to integrate these students into academic life, and support investigation into an exciting realm of ideas.

\section{References}

[1] Benson, L., "Education and Social Mobility among Minority Populations in Xinjiang." Ed. S. F. Starr. Xinjiang, China's Muslim Borderland. M.E. Sharpe, London, 2004, 190-215.

[2] Cesaro, M.C., "Consuming Identities: Food and Resistance among the Uyghurs in Contemporary Xinjiang." Inner Asia 2 (2), 2000, 225-38.

[3] China File Conversation, "Are ethnic tensions on the rise in China?" February 13, 2014.

[4] Dhami, S., and Sheikh, A., "The Muslim Family: Predicament and Promise." West Journal of Medicine November 173(5), 2000, pp.352-56.

[5] Evan-Hume, C. "Minzu University of China", $<$ http://suite101.com/article/ minzu-university- S.of-chinaa113718> 2009.

[6] Featherman, D. L., Hall, M. and Krislov, M., The Next Twenty-Five Years: Affirmative Action in Higher Education in the United States and South Africa. University of Michigan Press, Ann Arbor, 2009.

[7] Hansen, M.H., Lessons in Being Chinese: Minority Education and Ethnic Identity in South West China, University of Washington Press, Seattle, 2011. 
[8] Ives, M., "China: Time to Re-assess Minority Education”. World University News, 19 December, 2010.

[9] Karmody, E., Minority Education in Remote Regions of China", Current Research Journal of the Social Sciences. 4(2) 109-120, 2012.

[10] Postiglione, G. A., Ed., China's National Minority Education: Culture, Schooling, and Development, Garland Publishing, London.1998.

[11] Sacks, D., and Theil, P., "The case against Affirmative Action". Stanford Alumni Magazine, 2013. http://alumni.stanford.edu/get/page/magazine/article/?artic le_id $=43448$

[12] Sautman, B., Preferential Policies for Ethnic Minorities in China: The Case of Xinjiang Division of Social Science Hong Kong University of Science and Technology Working Papers in the Social Sciences No. 32, 1997.

[13] Sowell, T., Affirmative Action Around the World: An Empirical Study, Yale University Press, New Haven, 2004.

[14] R. Wang, and M. Wu, "Education for Ethnic Minorities in China: A Policy Critique." SA-e DUC Journal 6.2, 2009, pp. 117-31.

[15] Zhang, X., Gender and Uyghur-Han variation in arranged marriages in Urumchi; China Westminster Forum, Sheffield University, 15 October 2010. 